\title{
Laboreal
}

Volume 17 №2 | 2021

Trabalho e Território

\section{Atividade de trabalho, território, e seus protagonistas : para uma agenda do futuro - Introdução ao dossier}

Actividad de trabajo, territorio y sus protagonistas : hacia una agenda del futuro

- Introducción al dosier

Activité de travail, territoire et ses protagonistes : vers un agenda pour l'avenir Introduction au dossier

Work activity, territory, and its protagonists : towards an agenda for the futureIntroduction to the dossier

\section{Liliana Cunha}

\section{OpenEdition}

Journals

\section{Edição electrónica}

URL: https://journals.openedition.org/laboreal/18757

DOI: $10.4000 /$ laboreal. 18757

ISSN: 1646-5237

\section{Editora}

Universidade do Porto

\section{Refêrencia eletrónica}

Liliana Cunha, «Atividade de trabalho, território, e seus protagonistas : para uma agenda do futuro Introdução ao dossier», Laboreal [Online], Volume $17 \mathrm{~N}^{\circ} 2$ | 2021, posto online no dia 03 dezembro 2021, consultado o 05 dezembro 2021. URL: http://journals.openedition.org/laboreal/18757 ; DOI: https://doi.org/10.4000/laboreal.18757

Este documento foi criado de forma automática no dia 5 dezembro 2021

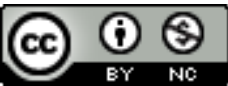

Laboreal está licenciado com uma Licença Creative Commons - Atribuição-NãoComercial 4.0 Internacional. 


\section{Atividade de trabalho, território, e seus protagonistas : para uma agenda do futuro - Introdução ao dossier}

Actividad de trabajo, territorio y sus protagonistas : hacia una agenda del futuro

- Introducción al dosier

Activité de travail, territoire et ses protagonistes : vers un agenda pour l'avenir Introduction au dossier

Work activity, territory, and its protagonists : towards an agenda for the futureIntroduction to the dossier

Liliana Cunha

\section{O encastramento territorial das atividades de trabalho}

1 As relações entre trabalho e território não se compadecem com análises stricto sensu (Schwartz, 2000) : são plurais, geograficamente situadas, e mobilizadoras de uma perspetiva de "tempo longo", capaz de recuperar a espessura temporal que permitiu a produção do território na configuração que lhe é, então, apreendida.

2 É dizer que as suas relações não são auto-explicativas, isto é, não se conformam com o mero princípio de que a atividade de trabalho é exercida num território, que pode ser conhecido e descrito; um território instituído como circunscrição política, e como produto da dinâmica de (alguns) atores sociais, ignorando outros debates de normas e de valores, protagonizados, designadamente, por trabalhadores/as desse território assumindo este tipo de abordagem o que Schwartz (1996) designou como uma "postura de exterritorialidade". 
3 A problematização do território admite, pois, a coexistência de diferentes questões que atravessam a sua discussão, como nos dão conta os textos que integram este dossier :

- a questão dos indicadores a privilegiar na sua análise (e.g., taxa de atividade; taxa de desemprego ; polos geradores de mobilidade; ...), ainda que esta seja frequentemente tida como um ponto de partida para dizer o que o território é, isto é, até se alcançar um "olhar a partir de dentro" (Cunha \& Lacomblez, 2012);

- a questão relativa à escala de regulação mais pertinente para uma "abordagem territorial", entre o que se passa a um nível macro e micro de análise, quando o território é, em si mesmo, síntese de diferentes escalas de análise (Reis, 2005);

- a questão da caracterização do território fazendo uso das categorias "urbano" e "rural", numa visão dualista, ou a afirmação do princípio de um continuum entre espaços marcados pela diversidade e pela heterogeneidade, e cujas fronteiras são necessariamente imprecisas (Veiga, 2005);

- e a questão dos territórios como espaços onde se constroem normas de Bem Comum, que também são atravessados por conflitos, pelo confronto com a alteridade ("de um nós face aos outros"), e pelo debate sobre o futuro desses espaços. É este ponto de vista que consubstancia o território como processo, e não como objeto de uma análise acrónica (Cunha, 2012).

Os textos que se enquadram no âmbito deste dossier evocam esta diversidade e, por isso mesmo, instigam a controvérsia. Mas, independentemente do ponto de vista assumido, partilham o princípio de encastramento territorial das atividades de trabalho, e arriscaria dizer, lembrando Leroi-Gourhan (1965) a propósito da noção de "espaço vital", uma representação comum de "um espaço ordenado em cujos limites podemos tocar num tempo compatível com a rotação das atividades quotidianas" [de trabalho] (p. 182, tradução livre).

5 Deixamos ao leitor o prazer da descoberta crítica face à abordagem do território que é imanente aos diferentes textos - ora como objeto de análise, como um a priori, ou um resultado disponível e suscetível de ser descrito, ora como um revelador (Lajarge, 2009) : do "processo da vida, quer dizer os modos como as sociedades se estruturam, os actores interagem e as referências colectivas se estabelecem" (Reis, 2007, pp. 23-24).

\section{A polissemia da questão territorial em cinco programas de pesquisa}

6 O dossier contempla cinco textos de autores de diferentes geografias: Chile, França, Portugal, Argentina e Bolívia, respetivamente.

- texto de Pamella Astudillo, Carlos Ibarra e Francisco Valdés abre este dossier apresentandonos dois estudos de caso desenvolvidos no quadro da indústria pesqueira fortemente disseminada por todo o território chileno, atendendo à sua extensão de Costa e a um reconhecido património de experiência na transformação dos produtos do mar. Uma análise "a partir de dentro" mostra como os territórios de trabalho neste setor interagem com a dimensão género.

A atividade de evisceração de ostras é feminina, predominantemente manual e marcada por metas de produção diária individual muito exigentes (cerca de $72 \mathrm{Kg}$ de ostras, assumindo um ritmo de evisceração de cada ostra a cada 4 segundos). À semelhança das análises que temos conduzido num setor bem distinto - setor da cortiça - também estas trabalhadoras 
reconhecem na observação das ostras a sua região de origem (Cunha, Silva, \& Lacomblez, 2021), e antecipam as dificuldades no seu trato (as regiões que produzem as ostras de melhor qualidade são também as que produzem ostras mais túrgidas e mais fáceis de manipular). Outras singularidades desta atividade, como as oscilações no fornecimento de matéria-prima de determinados tipos de qualidade, devido às condições climáticas; e as opções de organização do trabalho que definem metas de produtividade individualizadas e impermeáveis a estas variabilidades (à quantidade de ostras disponível para cada trabalhadora), instigam por vezes a competitividade pelas ostras no seio do coletivo de trabalho, e o conflito neste território.

No caso dos homens, a atividade é tradicionalmente associada ao descarregamento do pescado dos porões dos navios. Na cidade analisada, esta atividade foi marcada por uma importante crise nos anos '90, causada pelo fenómeno "El Niño", cujo impacto se fez sentir na diminuição de pescado, e no emprego. Na descarga é usada uma mangueira para inundar com água salgada, sob forte pressão, o pescado. Esta mangueira de grandes dimensões, designada entre os trabalhadores como "a pitão", é usada também para fazer a sucção, ou seja, o pescado é aspirado e transportado até à fábrica onde se fará o seu processamento. A dimensão das lanchas, o trabalho no mar com a embarcação em permanente movimento, o trabalho à noite, com fraca visibilidade e sob constrangimento temporal para evitar a degradação do pescado, são alguns dos riscos a que permanecem expostos estes trabalhadores.

As questões relativas à segurança e saúde no trabalho são discutidas relativamente aos recursos existentes no território, mostrando como as condições para a intervenção ergonómica não são independentes da história e da tradição inscrita nestes lugares.

- Fabienne Goutille e Alain Garrigou apresentam-nos a seguir um estudo, enquadrado no âmbito de um projeto financiado pelo Ministério da Agricultura francês e pela Região da Aquitânia, que ressalta a organização territorial como determinante no uso de produtos fitofarmacêuticos na atividade de viticultores. Como referem os autores, no território francês o uso de pesticidas agrícolas é marcadamente controverso : por um lado, o seu uso visa mitigar perdas substanciais que caracterizam este setor ; por outro lado, são conhecidos os seus impactos na saúde e no ambiente.

$\mathrm{O}$ aumento do conhecimento sobre os impactos associados ao uso de pesticidas tem contribuído, finalmente, para o reforço da regulamentação, e para promover a responsabilização individual, designadamente dos viticultores, relativamente a dificuldades coletivas, ignorando os debates que atravessam a sua atividade. É paradoxal esta constatação, tanto mais que o património para que a sua atividade contribui neste território tem uma história que lhe confere identidade e reconhecimento internacional.

A regulamentação desterritorializa a atividade. Os autores mostram como os viticultores são atores legítimos deste território e dão a ver como o seu ponto de vista deve ser convocado no debate sobre o seu futuro (Melé, 2009).

O território é aqui concetualizado como ação de diferentes atores e como lugar de coexistência de diferentes macro-determinantes da atividade de trabalho. É visível o conflito entre o aceitável e o inaceitável, o que é moral e ético, mas é sobre a atividade de trabalho dos viticultores que se espera um compromisso possível. Mesmo que o território seja entendido como recurso coletivo, fica-nos a imagem de uma descontinuidade topográfica neste território : é como se fosse dada uma existência primeira à regulamentação e aos atores políticos relativamente aos outros, cidadãos, de forma global, e cidadãostrabalhadores, em particular. 
- Quanto ao texto de Ana Azevedo, João Caramelo e Sofia Marques da Silva, os autores partem do reconhecimento de que falar sobre os territórios de atividade requer a consideração da diversidade socioeconómica dos territórios. A territorialização das políticas públicas em matéria de formação profissional é tributária das dinâmicas de emprego, da distribuição dos polos industriais, e dos processos de transformação tecnológica, que caracterizam o modelo de "Indústria 4.0" (I4.0).

A polissemia da questão territorial é reencontrada neste texto, pelo desafio de pensar o território para além da sua dimensão física/geográfica. A digitalização, a par da crise pandémica por COVID-19, como referido pelos autores, tornou emergentes formas de trabalho remoto e o recurso a sistemas digitais de comunicação, cujos impactos no território português e na atividade dos formadores se procurou explorar. A noção de território ciberfísico é imanente à reflexão trazida pelos autores, enquanto interação entre as suas formas física/geográfica e virtual/digital. O estudo conduzido visa contribuir para a proposta de um referencial de formação pedagógica de formadores, tendo em conta as transformações que caracterizam o paradigma de I4.0, e a distribuição desigual deste tipo de projetos no contexto industrial português.

Se, por um lado, os territórios são resultado de evoluções económicas e sociais que atravessam a sociedade, o artigo interroga o lugar e o posicionamento dos atores da formação sobre estas práticas de organização do trabalho, e a territorialização das políticas de formação (Gérard, 2010).

Fica ainda assim a interpelação : como a atividade de trabalho dos formadores protagoniza, neste novo cenário de atividade, a acomodação das políticas públicas às singularidades locais (Cunha, 2012) ? E, bem assim, que outras formas de invisibilidade se produzem no quadro destes territórios ciberfísicos?

- Prosseguindo esta reflexão sobre a invisibilidade, Pablo Schamber é o autor do texto que nos leva até à Cidade de Buenos Aires, e à atividade dos cartoneros. A regulação da atividade dos cartoneros através de políticas públicas de gestão de resíduos não permitiu dissipar a disputa pelo território, relativamente aos trabalhadores com outro estatuto de emprego (trabalhadores formais), nem a tentativa de afirmação de uma territorialidade própria, no contexto de um sistema de recolha diferenciada (resíduos secos vs. resíduos húmidos).

o texto desafia-nos a ultrapassar o dualismo macro-micro na análise das relações entre políticas públicas de gestão de resíduos, atividade e território, ao mesmo tempo que convoca, mesmo que não de forma explícita, a referência ao conceito de territorialidade, enquanto tentativa de apropriação do espaço, sem a presença do "outro". A pandemia marcou indelevelmente este conflito e a reprodução de desigualdades neste território, como se o território da atividade de uns mantivesse na penumbra o território dos outros.

Em prol da reconfiguração da malha urbana, o projeto de uma política pública de gestão integral dos resíduos (secos e húmidos) não pode escamotear as tensões que revelam as análises da atividade conduzidas neste contexto, nem os seus impactos.

- Finalmente, o texto de Tania Aillon faz-nos reencontrar mais eixos de reflexão, cruzando a atividade de trabalho, a mobilidade geográfica e social. Os territórios de trabalho são espaços socialmente produzidos, e cuja análise, na sua espessura temporal, permite melhor compreender. A vida no campo e na cidade é fortemente contrastada, a partir deste estudo desenvolvido em Cochabamba, na Bolívia. A trajetória laboral define espaços de ocupação urbana específicos, de que são exemplos os "bairros operários" retratados no texto.

0 acesso a uma atividade de trabalho "na fábrica" é perspetivado como uma melhoria das condições de vida, a garantia de maior estabilidade no emprego, mesmo se uma análise mais fina permite depois identificar diferentes formas de segregação dentro deste espaço urbano, 
nomeadamente, em função da origem, em função do género, e da interação entre estes fatores de desigualdade.

\section{O território como categoria de análise no estudo das atividades de trabalho}

7 Se tantos outros textos integrassem o dossier, provavelmente, outras perspetivas sobre o que é o território poderiam ser trazidas.

8 O território não é um objeto neutro, desconectado do real : ele é também produto da atividade de trabalho e da dinâmica dos seus diferentes protagonistas. É esta, aliás, a perspetiva que temos assumido no âmbito das nossas pesquisas, designadamente no setor dos transportes (Cunha \& Lacomblez, 2012, 2021) ou, mais recentemente, no setor da cortiça, como fizemos já referência. No nosso caso, explorar como o território é um dispositivo operatório para a ação e como a atividade de trabalho intervém nos processos de territorialização, são questões que têm marcado as nossas análises.

"Para uma agenda do futuro" fica, então, a expectativa de que este dossier possa contribuir para a construção de uma visão partilhada sobre o território enquanto categoria de análise no estudo das atividades de trabalho, conjugando a controvérsia com o debate, na definição também de outros territórios de investigação.

\section{BIBLIOGRAFIA}

Cunha, L. (2012). Mobilidades, territórios e serviço público : debates sobre o interesse colectivo à margem do paradigma de uma sociedade móvel (Tese de Doutoramento). Faculdade de Psicologia e de Ciências da Educação da Universidade do Porto, Portugal.

Cunha, L., \& Lacomblez, M. (2012). From the "terrain" to "territory" : which contributions from mobility and bus drivers' activity towards local development ? Work, 41, 6156-6161. https:// doi.org/10.3233/WOR-2012-1077-6156

Cunha, L., \& Lacomblez, M. (2021). Le territoire : un dispositif opératoire révélé par l'activité de travail. Activités, 18(2), 1-13. https://doi.org/10.4000/activites. 6925

Cunha, L., Silva, D., \& Lacomblez, M. (2021). Quando o trabalho é património de uma região : como pensar o desenvolvimento de um "projet-héritage" ? In L. Cunha, R. Di Ruzza, M. Lacomblez, Y. Schwartz, \& D. Silva (Eds.), Trabalho, Património e Desenvolvimentos - Travail, Patrimoine et Développements - Trabajo, Patrimonio y Desarrollos (pp. 195-201). Porto : Universidade do Porto FPCE.

Gérard, P. (2010). La formation professionnelle : clé pour l'innovation sociale, économique et territoriale. Education Permanente, 184, 27-36.

Lajarge, R. (2009). Pas de territorialisation sans action (et vice versa) ? In M. Vanier (Dir.), Territoires, territorialité, territorialisation : controverses et perspectives (pp. 193-204). Rennes : Presses Universitaires de Rennes. 
Leroi-Gourhan, A. (1965). Le geste et la parole. Paris : Albin Michel.

Melé, P. (2009). Identifier un régime de territorialité réflexive. In M. Vanier (Dir.), Territoires, territorialité, territorialisation : controverses et perspectives (pp. 45-56). Rennes : Presses Universitaires de Rennes.

Reis, J. (2005). Uma epistemologia do território. Estudos Sociedade e Agricultura, 13(1), 51-74.

Reis, J. (2007). Ensaios de economia impura. Coimbra : Almedina.

Schwartz, Y. (1996). Ergonomie, philosophie et exterritorialité. In F. Daniellou (Dir.), L'ergonomie en quête de ses principes : débats épistémologiques (pp. 141-182). Toulouse : Octares.

Schwartz, Y. (2000). Le paradigme ergologique ou un métier de philosophe. Toulouse : Octarès.

Veiga, J. (2005). Território e desenvolvimento local. Oeiras : Celta Editora.

\section{AUTOR}

\section{LILIANA CUNHA}

https://orcid.org/0000-0002-7362-9382,

Centro de Psicologia da Universidade do Porto ; Faculdade de Psicologia e de Ciências da Educação Universidade do Porto , Rua Alfredo Allen, 4200-135 Porto, Portugal lcunha@fpce.up.pt 